2011-TBD

\title{
Performance Characterization of a Microchannel Liquid/Liquid Heat Exchanger Throughout an Extended Duration Life Test
}

Rubik B. Sheth and Ryan A. Stephan NASA Johnson Space Center

Ebony Hawkins-Reynolds

GeoControls Systems Incorporated

\begin{abstract}
Liquid/Liquid Heat Exchangers (L/L HX) are an integral portion of any spacecraft active thermal control system. For this study the X-38 L/L HX was used as a baseline. As detailed in a previous ICES manuscript, NASA paired with Pacific Northwest National Laboratory to develop a Microchannel L/L HX (MHX). This microchannel HX was designed to meet the same performance characteristics as the aforementioned $\mathrm{X}-38 \mathrm{HX}$. The as designed Microchannel $\mathrm{HX}$ has a $26 \%$ and $60 \%$ reduction in mass and volume, respectively. Due to the inherently smaller flow passages the design team was concerned about fouling affecting performance during extended missions. To address this concern, NASA has developed a test stand and is currently performing an 18 month life test on the MHX. This report will detail the up-to-date performance of the MHX during life testing.
\end{abstract}




\title{
Performance Characterization of a Microchannel Liquid/Liquid Heat Exchanger Throughout an Extended Duration Life Test
}

\author{
Rubik Sheth ${ }^{1}$ \\ Johnson Space Center, Houston, Texas 77058 \\ and \\ Ryan Stephan ${ }^{2}$ \\ Johnson Space Center, Houston, Texas 77058
}

\begin{abstract}
Liquid/Liquid Heat Exchangers (L/L HX) are an integral portion of any spacecraft active thermal control system. For this study the X-38 L/L HX was used as a baseline. As detailed in a previous ICES manuscript, NASA paired with Pacific Northwest National Laboratory to develop a Microchannel L/L HX (MHX). This microchannel HX was designed to meet the same performance characteristics as the aforementioned X-38 HX. The Microchannel $\mathrm{HX}$ has a $26 \%$ and $60 \%$ reduction in mass and volume, respectively. Due to the inherently smaller flow passages the design team was concerned about fouling affecting performance during extended missions. To address this concern, NASA has developed a test stand and is currently performing an 18 month life test on the MHX. This report will detail the up-to-date performance of the MHX during life testing.
\end{abstract}

\section{Nomenclature}

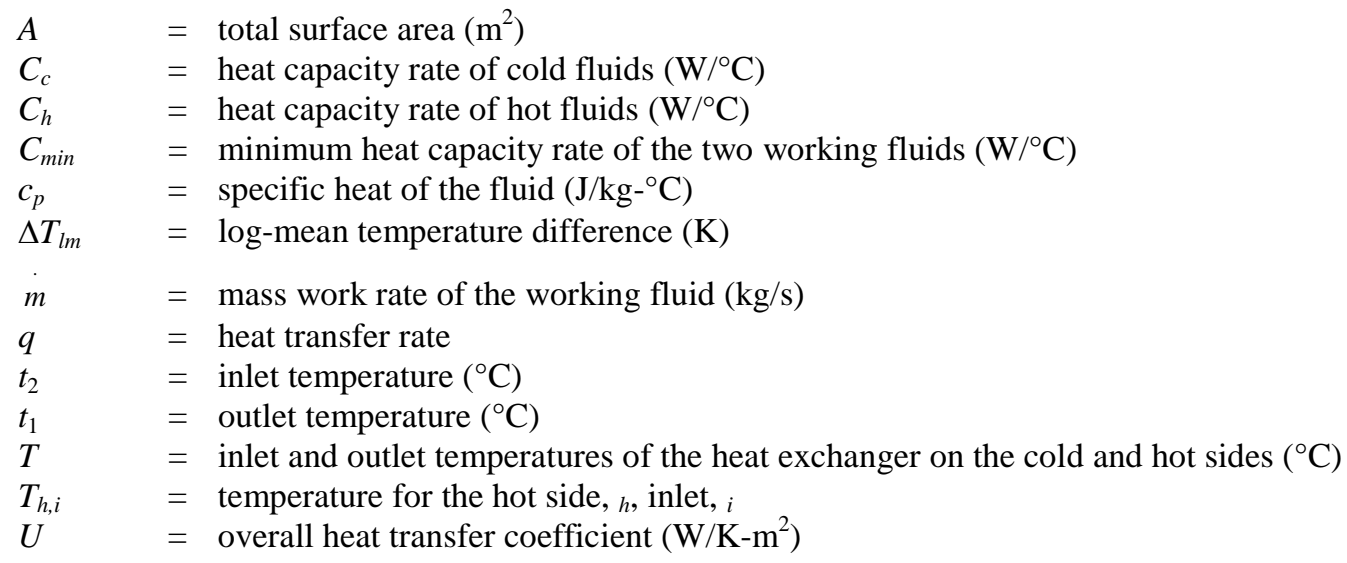

\section{Introduction}

Tn an effort to address the mass and volume concerns associated with space flight hardware, the Thermal Control ISystem Development for Exploration Project at the NASA Johnson Space Center partnered with Pacific Northwest

\footnotetext{
1,2 JSC Project Manager, Advanced Thermal Control Systems, 2101 NASA Parkway, Houston, Texas 77058
} 
National Laboratory (PNNL) to develop a microchannel liquid/liquid heat exchanger. PNNL expected that its technology would provide considerable mass and volume savings over state-of-the-art plate and fin heat exchangers.

PNNL designed and fabricated a microchannel liquid/liquid heat exchanger based on the performance criterion of a flight qualified plate and fin X-38 heat exchanger. The X-38 vehicle was designed to be used as an emergency crew return vehicle for the International Space Station. The microchannel heat exchanger was designed to transfer the same amount of heat as the X-38 heat exchanger and have equal or lower pressure drops for both the hot and the cold fluid sides. To corroborate PNNL's claims of volume and mass savings, the X-38 heat exchanger was tested at the design point and its performance was used as a baseline to compare with the microchannel heat exchanger's performance.

\section{MICROCHANNEL LIQUID/LIQUID HEAT EXCHANGER}

The microchannel heat exchanger was designed to meet or exceed the previously described X-38 heat exchanger requirements. PNNL fabricated the microchannel heat exchanger using stainless steel. The microchannel heat exchanger core measures 1.9 inches in length, 3 inches in width and 3.3 inches in height as shown in Figure 1. Channels inside the microchannel heat exchanger measure approximately $0.1-0.3 \mathrm{~mm}$, creating more wetted surface area and thus resulting in a higher thermal conductance.

Conventional plate and fin heat exchangers usually have low pressure drops because of the wider flow channels that allow the fluids to flow freely without added flow restrictions. Heat

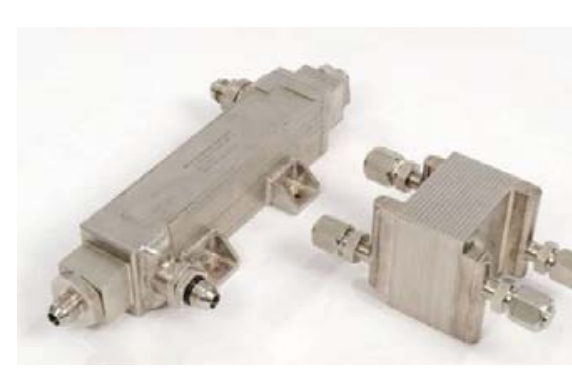

Figure 2. Comparison of X-38 and Microchannel Heat Exchangers

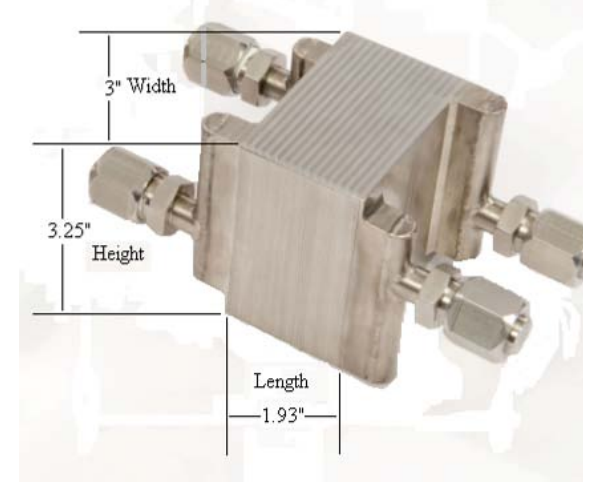

Figure 1. Dimensions of Microchannel Heat Exchanger Core PNNL's claim to the contrary, the Thermal Control System Development for Exploration Project was concerned that the microchannel heat exchanger would experience a higher pressure drop caused by the smaller flow channels.

Table 2 provides a comparison of the geometric specifications for the X-38 and microchannel heat exchangers. The mass and volume savings of the microchannel heat exchanger are evident. Figure 2 shows the two heat exchangers side by side. The difference in volume is noticeable.

Table 1. Heat exchangers geometric specifications

\begin{tabular}{|c|c|c|}
\hline Heat Exchanger & Mass & Core Volume \\
\hline X-38 & $2.7 \mathrm{~kg}$ & $48 \mathrm{in}^{3}$ \\
\hline Microchannel & $2 \mathrm{~kg}$ & $19 \mathrm{in}^{3}$ \\
\hline
\end{tabular}

\section{TEST SETUP}

Figure 3 shows the mechanical schematic of the test loop for the heat exchanger test apparatus. The test loop was developed using two fluid loops. The main loop also called the hot loop used deionized water as the working fluid at a heat exchanger inlet temperature of approximately $27^{\circ} \mathrm{C}$. The chiller loop was nominally chilled to an inlet temperature of $4^{\circ} \mathrm{C}$ and used 50:50 by mass ethylene glycol and water mixture as the working fluid. The inlet 
temperatures were based on the design point for the $\mathrm{X}-38$ heat exchanger. The X-38 and the microchannel heat exchangers were both individually tested in the test loop.

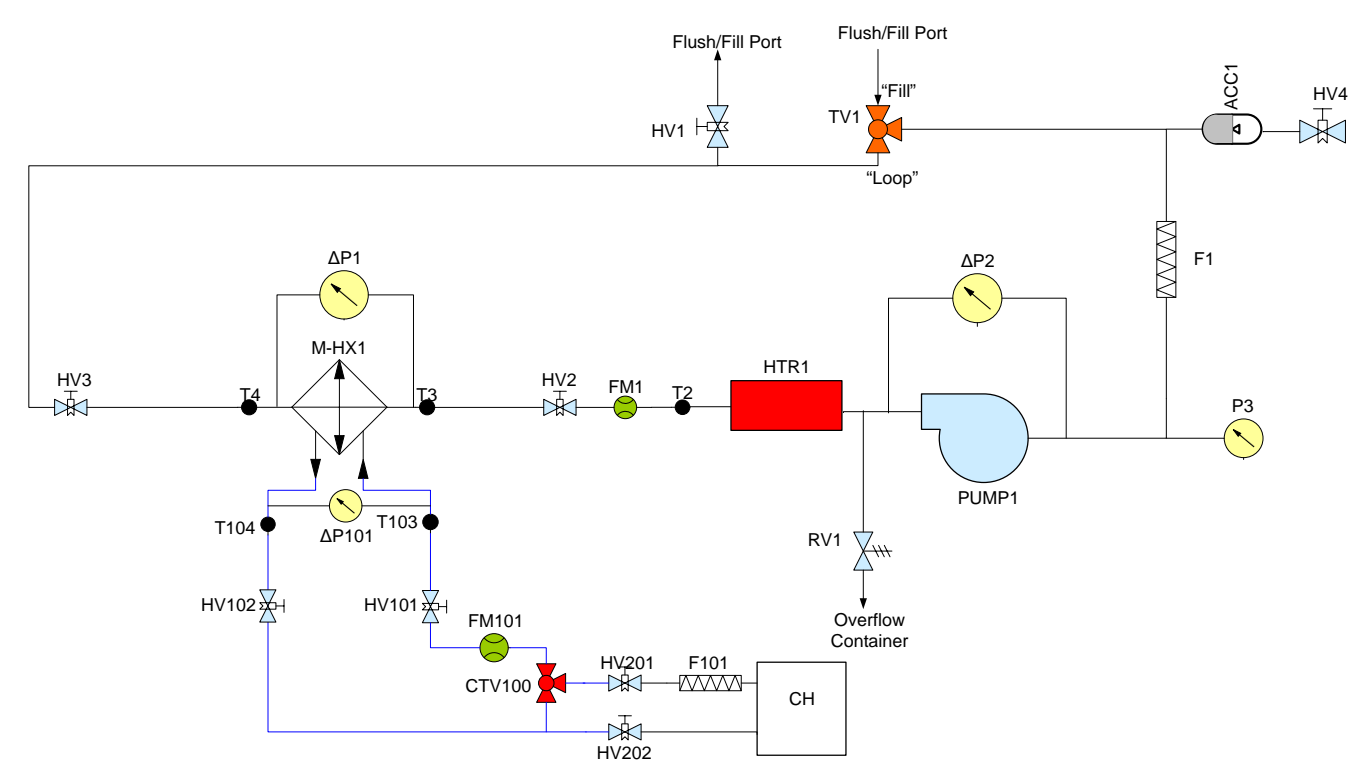

Figure 3. Microchannel test schematic

\section{Test Results}

The results discussed are taken from the primary test point: $350 \mathrm{lb} / \mathrm{hr}$ at an inlet temperature of $27^{\circ} \mathrm{C}$ on the main loop and $600 \mathrm{lb} / \mathrm{hr}$ at an inlet temperature of approximately $4^{\circ} \mathrm{C}$ on the cold loop. The X-38 and microchannel heat exchangers were designed to have a heat transfer rate of $3.1 \mathrm{~kW}$ and a maximum pressure drop of 0.5 psid across both the hot and cold sides. Table 3 shows the baseline test data for the X-38 and microchannel heat exchangers.

The X-38 heat exchanger failed to produce a heat transfer rate of $3.1 \mathrm{~kW}$, while the microchannel produced a higher heat transfer rate for the prescribed inlet conditions. It's failure to produce the designed heat transfer rate can

Table 3. X-38 and microchannel heat exchangers main test point and design point values

\begin{tabular}{|c|c|c|c|c|c|c|}
\cline { 2 - 7 } \multicolumn{1}{c|}{} & $\begin{array}{c}\mathbf{q}_{\text {hot }} \\
(\mathbf{W})\end{array}$ & $\begin{array}{c}\mathbf{q}_{\text {cold }} \\
\text { (W) }\end{array}$ & $\boldsymbol{\varepsilon}$ & $\begin{array}{c}\mathbf{U A} \\
(\mathbf{W} / \mathbf{k})\end{array}$ & $\begin{array}{c}\Delta \mathbf{P}_{\text {hot }} \\
\text { (psid) }\end{array}$ & $\begin{array}{c}\Delta \mathbf{P}_{\text {cold }} \\
\text { (psid) }\end{array}$ \\
\hline X-38 & $\begin{array}{c}2423 \pm \\
42\end{array}$ & $2662 \pm 40$ & $.65 \pm .01$ & $261 \pm 10$ & $0.35 \pm .005$ & $0.54 \pm .012$ \\
\hline Microchannel & $\begin{array}{c}3138 \pm \\
51\end{array}$ & $3317 \pm 44$ & $.84 \pm .01$ & $553 \pm 10$ & $0.48 \pm .029$ & $0.95 \pm .028$ \\
\hline Design Point & \multicolumn{2}{|c|}{$3100 \mathrm{~W}$} & .75 & 415 & 0.5 & 0.5 \\
\hline
\end{tabular}
possibly be attributed to the cleanliness of the heat exchanger or to possible fouling within the $\mathrm{X}-38$ heat exchanger. However, the project has every reason to believe the $\mathrm{X}$-38 heat exchanger did indeed meet its performance requirements when it was delivered to NASA. As mentioned above, the

X-38 heat exchanger was fabricated and intended to serve as flight hardware. NASA would not have taken delivery of the hardware if it was not shown to meets its performance requirement. The X-38 heat exchanger did meet the pressure drop requirement of less than 0.5 psid on both sides of the heat exchanger. In fact, the X-38 heat exchanger had a pressure drop of 0.35 psid across the hot side and 0.54 psid across the cold side. The microchannel heat 
exchanger met the pressure drop requirement across the hot side with a pressure drop of 0.48 psid, but failed across the cold side at 0.95 psid. This data was shared with PNNL who used the test data to correlate their design model. PNNL has subsequently claimed that they could deliver another heat exchanger that would meet the pressure drop requirements while sacrificing on heat transfer performance, which would be acceptable because their heat exchanger performance exceeded the design requirement. To be exact, PNNL claims that they can deliver a new heat exchanger that meets all of the design requirements and has a mass of only $1.2 \mathrm{~kg}$ and a core volume of 188 $\mathrm{cm}^{3}$.

To determine how efficient the heat exchangers were, effectiveness and overall heat transfer coefficient were calculated. The microchannel heat exchanger had a higher effectiveness and heat transfer coefficient than the X-38 heat exchanger. Effectiveness is a measure that determines how well a heat exchanger is able to transfer heat from one fluid to the other. As shown in Table 3, the microchannel heat exchanger's effectiveness was 0.84 compared to 0.65 for the X-38 heat exchanger. This increase in effectiveness was due to the microchannel heat exchanger having larger temperature differences between the inlet and outlet temperatures than the X-38 heat exchanger. The microchannel heat exchanger overall heat transfer coefficient was $553 \mathrm{~W} / \mathrm{K}$, which was more than double the overall heat transfer coefficient of the X-38 heat exchanger which was calculated to be $261 \mathrm{~W} / \mathrm{K}$. The difference in overall heat transfer coefficient is due to either a higher thermal resistance between the working fluids in the X-38 heat exchanger or a much higher surface area in the microchannel heat exchanger, or a combination of both.

\section{Conclusion}

A plate and fin liquid/liquid X-38 heat exchanger was originally designed to have a heat transfer rate of $3.1 \mathrm{~kW}$ and pressure drops not to exceed 0.5 psid across both the hot and cold sides of the heat exchanger. Performance specifications from this heat exchanger were used to design a microchannel liquid/liquid heat exchanger. A test apparatus was designed and used to test both the X-38 and the microchannel heat exchangers. The microchannel heat exchanger met all of its performance requirements, with the exception of the pressure drop across the cold side of the heat exchanger. The microchannel heat exchanger's heat transfer rate, effectiveness, and UA were higher although it weighs less and is smaller than the X-38 heat exchanger. The microchannel heat exchanger design achieved a mass reduction of $26 \%$. In addition, its core was reduced by $61 \%$ as compared to that of the X-38 heat exchanger.

The test data have been shared with PNNL. The project was especially concerned about PNNL's failure to meet the pressure drop requirements. To that end, PNNL has used the test data to develop correlated thermal models. These models were then used to conceptually design a next generation microchannel heat exchanger. The conceptual design shows improved mass and volume as compared to the first generation microchannel heat exchanger. This was achieved while sacrificing the unit's thermal performance. This sacrifice was acceptable because the first unit exceeded the thermal performance specifications. The mass and core volume for the conceptual design is $1.2 \mathrm{~kg}$ and $188 \mathrm{~cm}^{3}$, respectively.

The project is in the process of developing a life test for the microchannel heat exchanger. This test is scheduled to run the baseline test point continuously for at least 6 months. The life test will provide insight into the performance of a microchannel heat exchanger over a long test duration. The project is concerned that the microchannel heat exchanger may be susceptible to performance degradation because of the extremely small flow passages. 


\section{Appendix}

$\mathrm{X}$-38 heat exchanger test data with varying flow rates:

\begin{tabular}{|c|c|c|c|c|c|c|c|}
\hline $\begin{array}{c}\text { Flow } \\
\text { Ratehot } \\
\text { (Ib/hr) }\end{array}$ & $\begin{array}{c}\text { Flow } \\
\text { Ratecold } \\
\text { (Ib/hr) }\end{array}$ & qhot (W) & qcold (W) & $\boldsymbol{\varepsilon}$ & $\begin{array}{c}\text { UA } \\
\text { (W/K) }\end{array}$ & $\begin{array}{c}\Delta \text { Phot } \\
\text { (psid) }\end{array}$ & $\begin{array}{c}\Delta \text { Pcold } \\
\text { (psid) }\end{array}$ \\
\hline 351 & 600 & $2423 \pm 42$ & $2661 \pm 40$ & $0.65 \pm .01$ & $261 \pm 10$ & $0.36 \pm .005$ & $0.55 \pm .013$ \\
\hline 355 & 558 & $2220 \pm 39$ & $2470 \pm 38$ & $0.63 \pm .01$ & $256 \pm 10$ & $0.24 \pm .005$ & $0.47 \pm .013$ \\
\hline 354 & 499 & $2224 \pm 39$ & $2498 \pm 38$ & $0.61 \pm .01$ & $251 \pm 10$ & $0.23 \pm .005$ & $0.42 \pm .013$ \\
\hline 357 & 443 & $2161 \pm 39$ & $2388 \pm 37$ & $0.59 \pm .01$ & $258 \pm 10$ & $0.25 \pm .005$ & $0.34 \pm .013$ \\
\hline 354 & 400 & $2068 \pm 38$ & $2287 \pm 36$ & $0.60 \pm .01$ & $251 \pm 10$ & $0.25 \pm .005$ & $0.30 \pm .013$ \\
\hline 350 & 200 & $1476 \pm 32$ & $1597 \pm 41$ & $0.84 \pm .01$ & $248 \pm 10$ & $0.29 \pm .005$ & $0.09 \pm .013$ \\
\hline 350 & 151 & $1198 \pm 29$ & $1270 \pm 43$ & $0.90 \pm .02$ & $238 \pm 10$ & $0.29 \pm .005$ & $0.08 \pm .013$ \\
\hline 300 & 600 & $2278 \pm 43$ & $2521 \pm 40$ & $0.70 \pm .01$ & $248 \pm 10$ & $0.22 \pm .005$ & $0.56 \pm .013$ \\
\hline 250 & 600 & $2045 \pm 44$ & $2299 \pm 39$ & $0.75 \pm .01$ & $230 \pm 10$ & $0.17 \pm .005$ & $0.53 \pm .013$ \\
\hline 199 & 600 & $1672 \pm 44$ & $1902 \pm 37$ & $0.81 \pm .01$ & $209 \pm 10$ & $0.08 \pm .005$ & $0.60 \pm .013$ \\
\hline 150 & 600 & $1393 \pm 47$ & $1594 \pm 36$ & $0.87 \pm .01$ & $185 \pm 10$ & $0.05 \pm .005$ & $0.57 \pm .013$ \\
\hline
\end{tabular}

Microchannel heat exchanger test data with varying flow rates:

\begin{tabular}{|c|c|c|c|c|c|c|c|}
\hline $\begin{array}{c}\text { Flow } \\
\text { Ratehot } \\
\text { (Ib/hr) }\end{array}$ & $\begin{array}{c}\text { Flow } \\
\text { Ratecold } \\
\text { (Ib/hr) }\end{array}$ & qhot (W) & qcold (W) & $\boldsymbol{\varepsilon}$ & $\begin{array}{c}\text { UA } \\
\text { (W/K) }\end{array}$ & $\begin{array}{c}\Delta \text { Phot } \\
\text { (psid) }\end{array}$ & $\begin{array}{c}\Delta \text { Pcold } \\
\text { (psid) }\end{array}$ \\
\hline 350 & 601 & $3136 \pm 51$ & $3285 \pm 44$ & $0.84 \pm .01$ & $547 \pm 10$ & $0.48 \pm .028$ & $0.96 \pm .029$ \\
\hline 351 & 557 & $3060 \pm 50$ & $3284 \pm 43$ & $0.82 \pm .01$ & $551 \pm 10$ & $0.46 \pm .023$ & $0.84 \pm .030$ \\
\hline 350 & 499 & $2944 \pm 48$ & $3089 \pm 42$ & $0.80 \pm .01$ & $555 \pm 10$ & $0.46 \pm .023$ & $0.74 \pm .030$ \\
\hline 350 & 452 & $2811 \pm 47$ & $2965 \pm 42$ & $0.77 \pm .01$ & $554 \pm 10$ & $0.46 \pm .027$ & $0.63 \pm .030$ \\
\hline 350 & 406 & $2782 \pm 46$ & $2935 \pm 43$ & $0.76 \pm .01$ & $552 \pm 10$ & $0.47 \pm .030$ & $0.59 \pm .030$ \\
\hline 350 & 357 & $2565 \pm 44$ & $2680 \pm 43$ & $0.82 \pm .01$ & $562 \pm 10$ & $0.45 \pm .036$ & $0.48 \pm .030$ \\
\hline 350 & 301 & $2359 \pm 41$ & $2479 \pm 45$ & $0.87 \pm .01$ & $566 \pm 10$ & $0.45 \pm .042$ & $0.38 \pm .031$ \\
\hline 350 & 247 & $2058 \pm 38$ & $2163 \pm 46$ & $0.92 \pm .01$ & $610 \pm 10$ & $0.45 \pm .046$ & $0.31 \pm .031$ \\
\hline 351 & 209 & $1748 \pm 34$ & $1833 \pm 46$ & $0.95 \pm .01$ & $1006 \pm 10$ & $0.43 \pm .048$ & $0.28 \pm .033$ \\
\hline 300 & 599 & $2834 \pm 51$ & $2990 \pm 42$ & $0.88 \pm .01$ & $520 \pm 10$ & $0.43 \pm .028$ & $0.98 \pm .033$ \\
\hline 251 & 598 & $2464 \pm 52$ & $2620 \pm 40$ & $0.91 \pm .01$ & $469 \pm 10$ & $0.36 \pm .031$ & $1.04 \pm .036$ \\
\hline 201 & 598 & $2016 \pm 52$ & $2196 \pm 38$ & $0.94 \pm .01$ & $395 \pm 10$ & $0.3 \pm .032$ & $1.07 \pm .040$ \\
\hline 149 & 598 & $1517 \pm 52$ & $1655 \pm 36$ & $0.95 \pm .01$ & $282 \pm 10$ & $0.23 \pm .032$ & $1.06 \pm .044$ \\
\hline
\end{tabular}

\section{References}

${ }^{1}$ Incopera, F. P., and DeWitt, D. P., Fundamentals of Heat and Mass Transfer, $4^{\text {th }}$ ed., John Wiley \& Sons, New York, 1996. 